\title{
SISTEM INFORMASI PEMBERIAN BANTUAN SOSIAL DI DINAS SOSIAL, PEMBERDAYAAN PEREMPUAN, PERLINDUNGAN ANAK, PENGENDALIAN PENDUDUK DAN KELUARGA BERENCANA (P3AP2KB) KABUPATEN KUDUS BERBASIS WEB MENGGUNAKAN NOTIFIKASI SMS
}

\author{
Sonia Shekha Anggriani ${ }^{1}$, Wiwit Agus Triyanto ${ }^{2}$, Diana Laily Fithri ${ }^{3}$ \\ 1,2,3 Prodi Sistem Informasi, Universitas Muria Kudus \\ Email: ${ }^{1}$ soniashekha98@gmail.com, $\underline{\text { at.wiwit@umk.ac.id, }} \underline{{ }^{3} \text { diana.laily@umk.ac.id }}$
}

(Naskah masuk: 8 Desember 2020, diterima untuk diterbitkan: 30 Desember 2020)

\begin{abstract}
Abstrak
Penelitian skripsi yang berjudul "Sistem Informasi Pemberian Bantuan Sosial Di Dinas Sosial, Pemberdayaan Perempuan, Perlindungan Anak, Pengendalian Penduduk Dan Keluarga Berencana (P3AP2KB) Kabupaten Kudus Berbasis Web Menggunakan Notifikasi SMS" bertujuan untuk menghasilkan sebuah sistem yang dapat memudahkan Pihak Dinas Sosial P3AP2KB Kabupaten Kudus dalam memberikan bantuan sosial kepada warga yang berhak menerima bantuan tersebut khususnya pada pemberian santunan kematian, santunan anak yatim dan bantuan sosial bedah rumah. Selain itu juga dapat membantu masyarakat Kabupaten Kudus yang akan mengajukan bantuan sosial ke Dinas Sosial P3AP2KB. Dalam penelitian ini menggunakan metode observasi dan wawancara dengan pihak Dinas Sosial P3AP2KB Kabupaten Kudus. Metode pengembangan sistem yang digunakan dalam penelitian ini adalah pengembangan sistem Waterfall dengan tahapan tahapannya adalah Investigasi, Analisis Sistem, Desain, Implementasi, Maintenance. Perancangan sistem informasi yang digunakan adalah Flow of Document (FOD) dan Unified Modelling Language (UML) yang diharapkan dapat menghasilkan rancangan sistem baru yang lebih baik dan dapat menyelesaikan permasalahan yang ada.
\end{abstract}

Kata kunci: pemberian santunan, waterfall, UML, FOD

Abstract

The thesis research entitled "Information System for Providing Social Assistance at the Social Service, Women Empowerment, Child Protection, Population Control and Family Planning (P3AP2KB) Web-based Kudus Regency Using SMS Notification" aims to produce a system that can facilitate the Social Service Office of P3AP2KB, Kudus Regency. in providing social assistance to residents who are entitled to receive such assistance, especially in the provision of compensation for death, compensation for orphans and social assistance for house renovation. In addition, it can also help the people of Kudus Regency who will apply for social assistance to the P3AP2KB Social Service. In this study using the method of observation and interviews with the Department of Social Affairs P3AP2KB Kudus Regency. The system development method used in this research is the Waterfall system development with the stages of the stages are Investigation, System Analysis, Design, Implementation, Maintenance. The information system design used is Flow of Document (FOD) and Unified Modeling Language (UML) which are expected to produce a new system design that is better and can solve existing problems.

Keywords: giving compensation, waterfall, UML, FOD

\section{PENDAHULUAN}

Dinas Sosial, Pemberdayaan Perempuan, Perlindungan Anak, Pengendalian Penduduk dan Keluarga Berencana (P3AP2KB) adalah suatu instansi pemerintahan di Kabupaten Kudus yang terletak di Desa Mlati Kidul Kecamatan Kota Kabupaten Kudus yang bertugas sebagai penyelenggara kebijakan, program dan kegiatan di bidang pelayanan rehabilitasi sosial, bantuan perlindungan dan jaminan sosial, pemberdayaan kelembagaan sosial dan keluarga miskin,pemberdayaan perempuan dan perlindungan anak, pengendalian penduduk dan keluarga berencana. Dinas Sosial P3AP2KB memberikan berbagai layanan bagi masyarakat diantaranya memberikan bantuan santunan kematian, bantuan santunan yatim piatu dan bantuan sosial bedah rumah. 
Dinas Sosial P3AP2KB memberikan bantuan santunan kematian kepada warga Kabupaten Kudus yang memiliki kondisi ekonomi yang kurang mampu, pihak keluarga dapat mengajukan bantuan santunan kematian ke Dinas Sosial P3AP2KB dengan datang langsung dengan membawa berkas persyaratan yang telah ditentukan. Setelah pengajuan bantuan disetujui oleh pihak dinas maka pihak keluarga tersebut berhak menerima santunan kematian sebesar 1.000.000.

Selain bantuan santunan kematian Dinas Sosial P3AP2KB juga memberikan bantuan santunan anak yatim piatu dibawah usia 15 tahun yang diajukan oleh pihak desa dengan datang ke dinas membawa berkas persyaratan berupa Surat Keterangan Tidak Mampu (KTM), Kartu Keluarga (KK) dan tiap anak akan mendapat santunan sebesar 250.000 dalam 1 tahun.

Bagi warga Kabupaten Kudus yang memiliki tempat tinggal tidak layak huni dapat mengajukan bantuan sosial bedah rumah ke Dinas Sosial P3AP2KB dengan membawa Kartu Tanda Penduduk (KTP), Kartu Keluarga (KK), foto kondisi rumah yang ditempati, surat permohonan dan sertifikat tanah jika ada.

Dengan adanya berbagai layanan bantuan sosial yang ada di Dinas Sosial P3AP2KB ini diharapkan dapat membantu anak yatim piatu, warga Kabupaten Kudus yang berada dalam kondisi kurang mampu serta warga yang berada di lingkungan tempat tinggal kurang layak. Namun dalam proses pengajuan bantuan sosial mengalami kesulitan ketika warga harus datang berulang kali ke dinas untuk mengetahui apakah ajuan santunan nya disetujui atau tidak karena ketika berkas persyaratan kurang lengkap maka warga harus melengkapi berkas persyaratannya dulu dan mengajukan berkas nya lagi dengan datang ke dinas. Selain itu dikarenakan banyaknya warga yang mengajukan bantuan sosial terjadi penumpukan berkas di kantor dinas yang membuat pihak dinas mengalami kesulitan dalam pencarian berkas pengajuan bantuan sosial untuk diverifikasi. Pihak Dinas juga mengalami kesulitan dalam mengecek apakah data warga yang sudah mendapatkan bantuan sosial dan yang belum pernah mendapat bantuan sehingga membutuhkan waktu yang cukup lama untuk melihat data satu per satu warga yang telah mendapatkan bantunan selain itu juga untuk meminimalisir terjadinya kesalahan dalam pendataan sehingga warga yang sudah pernah mendapat bantunan akan mendapatkan lagi untuk yang kedua kalinya. Ketika pihak dinas membuat laporan mengenai data warga yang telah mendapatkan bantuan sosial untuk diserahkan ke Kepala Dinas juga mengalami kesulitan karena harus menulis data satu per satu dan tentunya hal ini membutuhkan waktu yang cukup lama.

Oleh karena itu, untuk membantu memudahkan warga Kabupaten Kudus yang akan mengajukan bantuan sosial ke Dinas Sosial P3AP2KB serta memudahkan pihak Dinas Sosial P3AP2KB dalam memberikan bantuan sosial kepada warga yang berhak menerima bantuan sosial dan juga untuk memudahkan dalam merekap dan mencetak laporan data maka penulis akan membangun sebuah sistem informasi pemberian bantuan sosial di Dinas Sosial, Pemberdayaan Perempuan, Perlindungan Anak, Pengendalian Penduduk dan Keluarga Berencana (P3AP2KB) berbasis web menggunakan notifikasi sms.

Rumusan masalah dalam penelitian ini yaitu bagaimana merancang dan membangun suatu sistem informasi pemberian bantuan sosial di Dinas Sosial, Pemberdayaan Perempuan, Perlindungan Anak, Pengendalian Penduduk dan Keluarga Berencana (P3AP2KB). Sehingga memudahkan warga dan pihak dinas dalam memberikan bantuan sosial dan memudahkan warga dalam mengajukan bantuan sosial.

Tujuan masalah dalam penelitian ini adalah sebagai berikut: (1) Menghasilkan sistem informasi yang dapat membantu warga dalam pengajuan bantuan sosial kepada Dinas Sosial P3AP2KB. (2) Menghasilkan suatu sistem yang dapat membantu pihak dinas dalam mendata warga yang mengajukan bantuan sosial dan memvalidasi berkas persyaratan yang diajukan oleh warga. (3) Menghasilkan sistem yang memudahkan Kepala Dinas dalam melihat laporan bantuan sosial yang telah diberikan kepada warga yang membutuhkan.

\section{LANDASAN TEORI}

\subsection{Pengertian Sistem}

Pengertian sistem menurut Jogiyanto HM (2005) merupakan kumpulan dari elemen-elemen yang berinteraksi untuk mencapai suatu tujuan tertentu. Sistem ini menggambarkan suatu kejadiankejadian dan kesatuan yang nyata, seperti tempat, benda dan orang-orang yang betul-betul ada dan terjadi.

\subsection{Pengertian Informasi}

Pengertian Informasi menurut Jogiyanto HM (1999: 692) merupakan hasil dari pengolahan data dalam suatu bentuk yang lebih berguna dan lebih berarti bagi penerimanya yang menggambarkan suatu kejadian - kejadian (event) yang nyata (fact) yang digunakan untuk pengambilan keputusan.

\subsection{Pengertian Bantuan Sosial}

Menurut Kementerian Sosial (2011) bantuan sosial adalah bantuan yang sifatnya sementara yang diberikan kepada masyarakat miskin, dengan maksud agar mereka dapat meningkatkan kehidupannya secara wajar.

\subsection{Pengertian Notifikasi}

Pengertian notifikasi menurut kamus besar bahasa indonesia adalah pemberitahuan atau kabar 
tentang penawaran barang dan sebagainya. https://kbbi.web.id/notifikasi (diakses pada tanggal 14 Mei 2020).

\section{TINJAUAN PUSTAKA}

Menurut Julian (2016) dalam penelitian tentang Sistem Informasi Bantuan Sosial Bagian Kesra Setda Kabupaten Sumedang yang menjelaskan bahwa aplikasi ini merupakan suatu upaya dalam meningkatkan pelayanan terhadap masyarakat yang ditandai dengan kondisi kehidupan masyarakat Sumedang yang memenuhi standar kelayakan dalam pemenuhan kebutuhan di bidang keagamaan, sosial dan pendidikan. Diharapkan system ini dapat melakukan pengelolaan yang lebih terkomputerisasi dari sisi pengolahan data dan penyimpanan data dalam database sehingga dapat menghasilkan proses pelayanan yang lebih baik pada kegiatan bantuan sosial di Bagian Kesejahteraan Rakyat Setda Kabupaten Sumedang. Namun penelitian tersebut hanya membahas pengolahan data dan penyimpanan data secara terkomputerisasi.

Menurut Tone (2016) dalam penelitian tentang Rancang Bangun Sistem Informasi Distribusi Bantuan Sosial Beras Miskin (Studi Kasus Kecamatan Binamu Kabupaten Jeneponto) yang menjelaskan bagaimana merancang dan membangun sistem informasi distribusi raskin yang dapat dipergunakan sebagai instrument pendukung tercapainya administrasi data yang baik dan mendorong transparansi proses distribusi raskin yang berjalan. Sistem ini juga diharapkan dapat mengontrol pendistribusian raskin agar tidak terjadi modus penyelewangan yang selama ini terjadi di Kecamatan Binamu.

\section{HASIL DAN PEMBAHASAN}

\subsection{Perancangan}

UML (Unified Modelling Language) adalah sebuah standarisasi bahasa pemodelan untuk pembangunan atau perancangan perangkat lunak yang dibangun dengan menggunakan teknik pemrograman berorientasi objek. Jenis-jenis diagram UML adalah sebagai berikut :

\section{Diagram Use Case}

Bisnis Use Case merupakan sebuah alat untuk mengidentifikasi dan menggambarkan keseluruhan proses bisnis yang berpengaruh di dalam sistem. Bisnis use case sistem informasi pemberian bantuan sosial di Dinas Sosial P3AP2KB Kabupaten Kudus Berbasis Web Menggunakan Notifikasi SMS dapat dilihat pada gambar 1 .

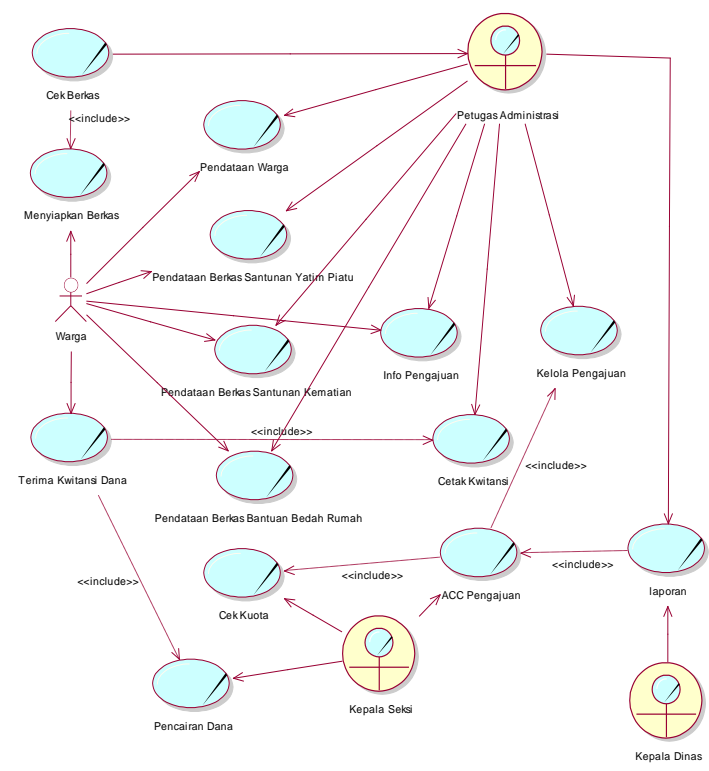

Gambar 1. Bisnis use case sistem informasi pemberian bantuan sosial di Dinas Sosial P3AP2KB Kabupaten Kudus Berbasis Web Menggunakan Notifikasi SMS

Di dalam diagram sistem use case yang memaparkan tentang aktor atau pelaku yang melakukan aktivitas dalam menggunakan hak akses di dalam sistem use case. Dari gambaran proses diagram business use case dapat digambarkan pula dengan proses diagram sistem use case. Sistem use case sistem informasi pemberian bantuan sosial di Dinas Sosial P3AP2KB Kabupaten Kudus Berbasis Web Menggunakan Notifikasi SMS dapat dilihat pada gambar 2 .

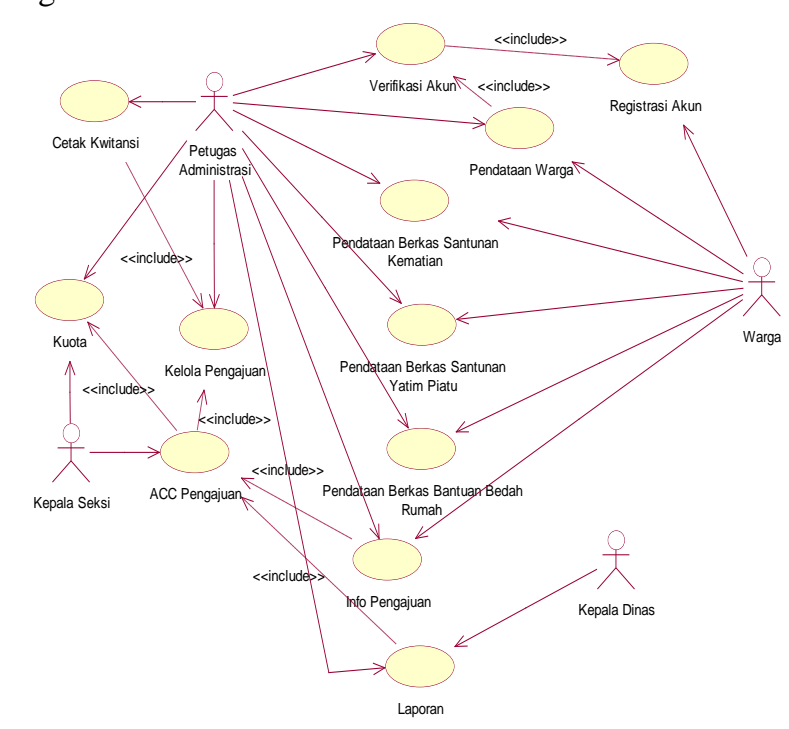

Gambar 2. Sistem use case sistem informasi pemberian bantuan sosial di Dinas Sosial P3AP2KB Kabupaten Kudus Berbasis Web Menggunakan Notifikasi SMS

Class Diagram adalah diagram yang digunakan untuk menggambarkan struktur sistem dari segi pendefinisian kelas-kelas yang akan dibuat untuk membangun sistem. Class diagram sistem informasi pemberian bantuan sosial di Dinas Sosial P3AP2KB 
Kabupaten Kudus Berbasis Web Menggunakan Notifikasi SMS dapat dilihat pada gambar 3.

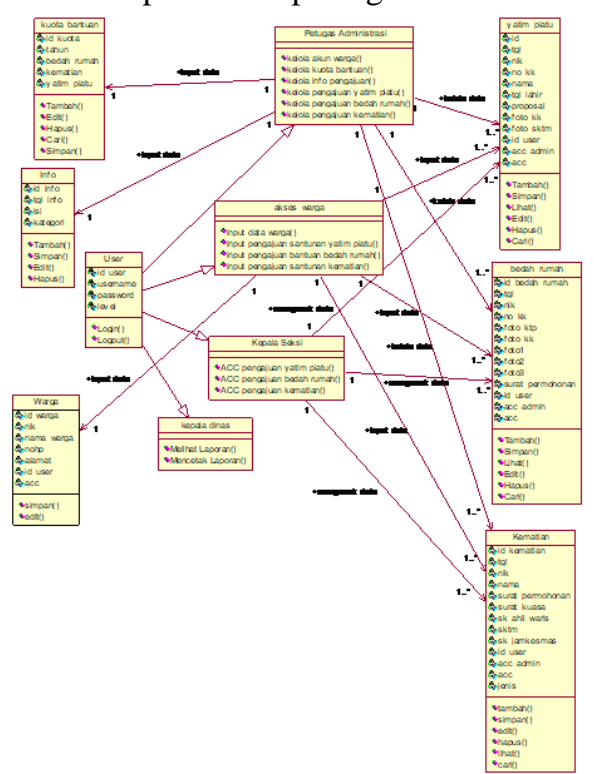

Gambar 3. Class diagram sistem informasi pemberian bantuan sosial di Dinas Sosial P3AP2KB Kabupaten Kudus Berbasis Web Menggunakan Notifikasi SMS

Diagram hubungan entitas atau yang lebih dikenal dengan sebutan ERD adalah notasi grafik dari sebuah model data atau sebuah model jaringan yang menjelaskan tentang data yang tersimpan (storage data) dalam sistem secara abstrak. ERD sistem informasi pemberian bantuan sosial di Dinas Sosial P3AP2KB Kabupaten Kudus Berbasis Web Menggunakan Notifikasi SMS dapat dilihat pada gambar 4.

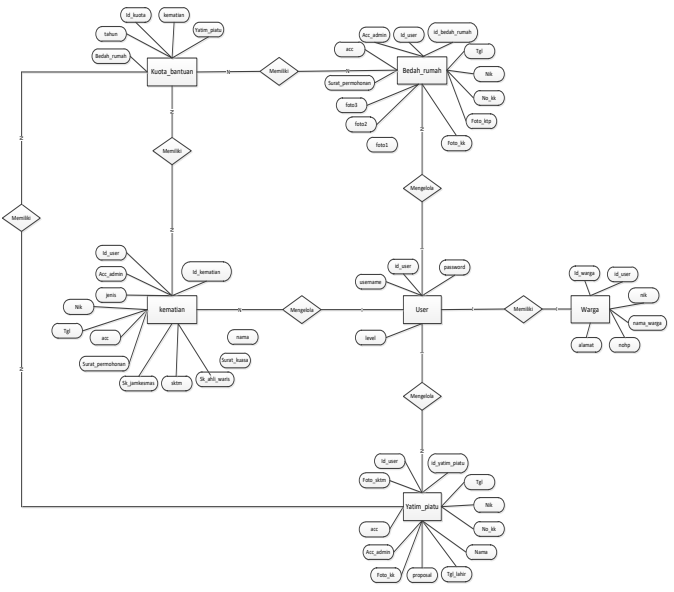

Gambar 4. ERD Sistem Informasi Pemberian Bantuan Sosial Di Dinas Sosial P3AP2KB Kabupaten Kudus Berbasis Web Menggunakan Notifikasi SMS

Relasi tabel pada basis data yang terbentuk untuk pembuatan sistem informasi bantuan sosial di Dinas Sosial P3AP2KB Kabupaten Kudus dapat dilihat pada gambar 5 berikut.
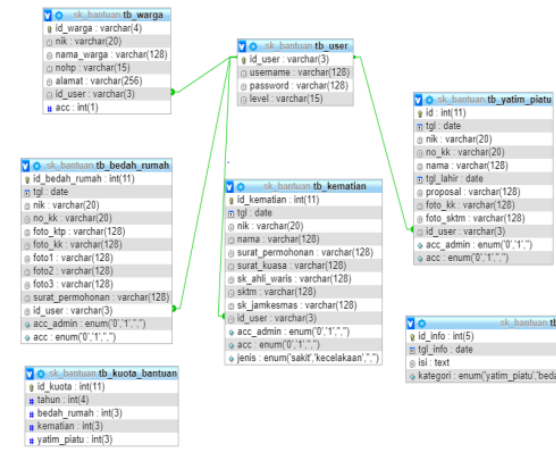

Gambar 5. Relasi Tabel Sistem Informasi Pemberian Bantuan Sosial Di Dinas Sosial P3AP2KB Kabupaten Kudus Berbasis Web Menggunakan Notifikasi SMS

\subsection{Implementasi}

Halaman login user merupakan halaman yang digunakan oleh user aplikasi (Warga, Petugas Administrasi, Kepala Seksi dan Kepala Dinas) untuk mengakses kedalam sistem. Tampilan dari halaman login user dapat dilihat pada gambar 6.

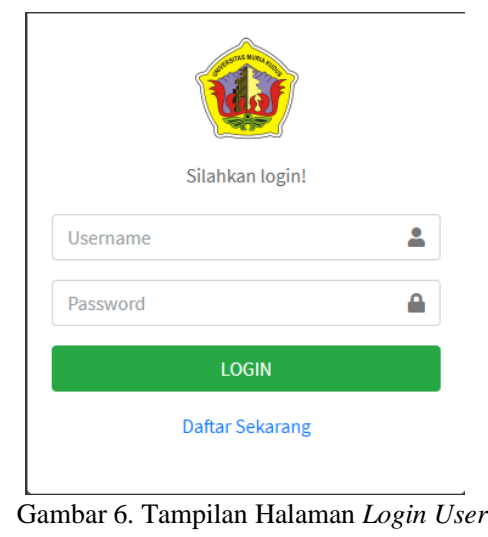

Halaman kelola data pengajuan santunan yatim piatu merupakan halaman yang digunakan oleh warga untuk meemasukkan data pengajuan santunan yatim piatu kedalam sistem. Terdapat button tambah, ubah, hapus dan cari. Tampilan dari halaman kelola data pengajuan santunan yatim piatu dapat dilihat pada gambar 7 .

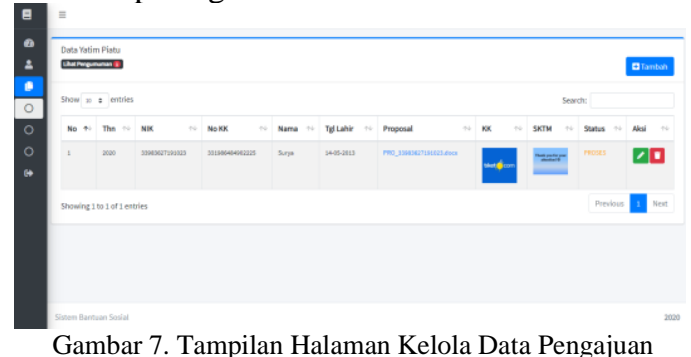

Gambar 7. Tampilan Halaman Kelola Data Pengajuan Santunan Yatim

Halaman kelola data pengajuan bantuan bedah rumah merupakan halaman yang digunakan oleh warga untuk memasukkan data pengajuan bantuan bedah rumah kedalam sistem. Terdapat button tambah, ubah, hapus dan cari. Tampilan dari halaman kelola data pengajuan bantuan bedah rumah dapat dilihat pada gambar 8 . 


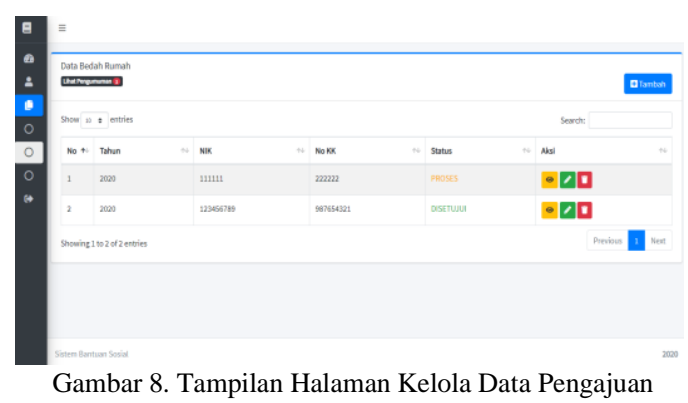
Bantuan Bedah Rumah

Halaman kelola data pengajuan santunan kematian merupakan halaman yang digunakan oleh warga untuk memasukkan data pengajuan santunan kematian ke dalam sistem. Terdapat button tambah, ubah, hapus dan cari. Tampilan dari halaman kelola data pengajuan santunan kematian dapat dilihat pada gambar 9.

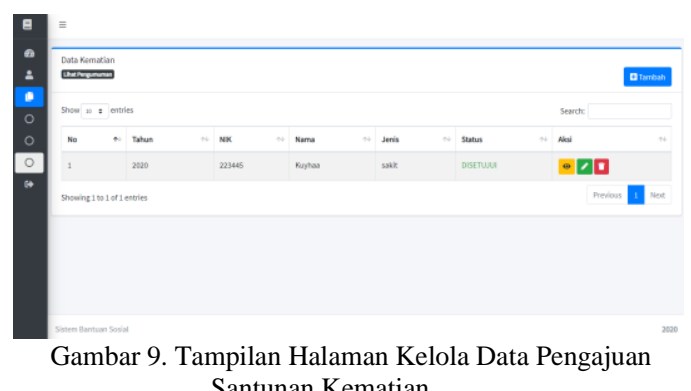
Santunan Kematian

Notifikasi sms menggunakan zenziva merupakan suatu informasi yang diberikan kepada warga yang mengajukan bantuan sosial pada Dinas Sosial P3AP2KB Kabupaten Kudus bahwa pengajuan bantuan sosial disetujui oleh pihak dinas. Tampilan notifikasi sms dapat dilihat pada gambar 10.

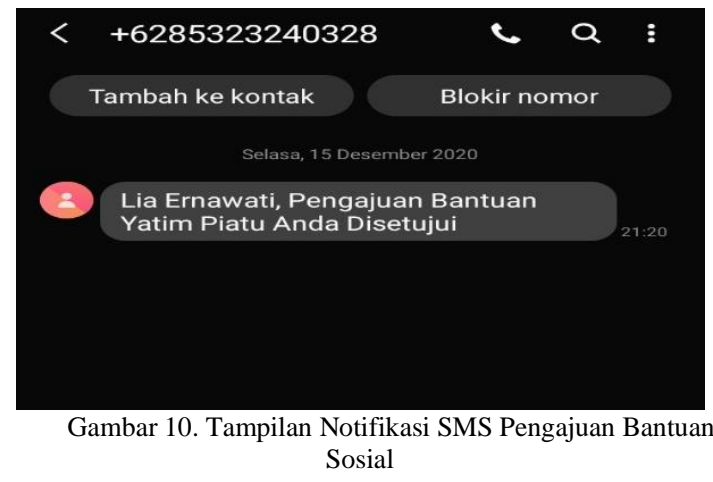

\section{KESIMPULAN DAN SARAN}

Berdasarkan hasil analisis dan perancangan, implementasi, serta pembahasan yang telah diuraikan di setiap bab-bab diatas dapat diambil beberapa kesimpulan sebagai berikut: (1) Sistem Informasi Pemberian bantuan sosial di Dinas Sosial, Pemberdayaan Perempuan, Perlindungan Anak, Pengendalian Penduduk dan Keluarga Berencana
(P3AP2KB) berbasis web menggunakan notifikasi sms ini dibangun dengan menggunakan bahasa pemrogaman PHP dan dengan database MySQL. (2) Sistem ini dibangun untuk mengelola data bantuan sosial untuk warga yang meliputi data warga, data ajuan santunan yatim piatu, data ajuan bantuan bedah rumah, data ajuan santunan kematian, data kuota bantuan dan data info pengajuan. (3) Sistem ini menghasilkan informasi yang sangat dibutuhkan oleh warga mengenai ajuan bantunan sosial yang diajukan kepada dinas. (4) Sistem ini menghasilkan informasi laporan bantuan sosial yang berguna untuk Kepala Dinas

Berdasarkan kesimpulan yang telah diuraikan diatas, maka penulis memberikan beberapa saran sebagai berikut: (1) Diharapkan mampu melengkapi kekurangan dari sistem yang telah dibangun. (2) Sistem ini masih berbasis web, diharapkan program ini dapat dikembangkan lebih lanjut menggunakan teknologi berbasis android yang lebih baik sehingga pihak dinas bisa melakukan pengecekan laporan bantuan sosial di Dinas Sosial P3AP2KB secara langsung melalui aplikasi smartphone.

\section{DAFTAR PUSTAKA}

Julian, E. 2016. Sistem Informasi Bantuan Sosial Bagian Kesra Setda Kabupaten Sumedang. STMIK Sumedang. Sumedang.

Sukamto, R.A, Shalahuddin, M. (2011). Pembelajaran Rekayasa Perangkat Lunak (Terstruktur dan Berorientasi Objek). Bandung: Informatika.

Tone, K. 2016. Rancang Bangun Sistem Informasi Distribusi Bantuan Sosial Beras Miskin (Studi Kasus Kecamatan Binamu Kabupaten Jeneponto). UIN Alauddin. Makassar. 